\title{
Effect of Room Condition on Sweetening and other Chemical Components of Different Cultivars of Potato in Swat District
}

\author{
Shujaat Ali ${ }^{1,2 *}$, Tariq Ahmad Jan ${ }^{3}$, Khalil Ur Rahman ${ }^{3}$, Shah Masaud Khan ${ }^{2}$, Ijaz Hussain ${ }^{2}$, Waseem \\ Ahmad $^{2}$, Qasim Ayub ${ }^{2}$, Muhammad Abbas ${ }^{1}$ and Israr Ahmad ${ }^{1}$
}

${ }^{1}$ Department of Horticulture Faculty of Crop Production Sciences, The University of Agriculture Peshawar, Khyber Pakhtunkhwa, Pakistan; ${ }^{2}$ Department of Agricultural Sciences, University of Haripur, Khyber Pakhtunkhwa, Pakistan; ${ }^{3}$ Agriculture Research Institute North Mingora Swat, Khyber Pakbtunkhwa, Pakistan.

\begin{abstract}
The lab experiment was conducted in 2016-2017, to evaluate the influence of storage at room condition on sweetening and other chemical components of potato tubers in Swat District, Pakistan. Tubers of the three cultivars, Desiree Diamont and Kruda were stored at room condition in three replications for 90 days. Data was recorded at 0 day (fresh) and at 15 days interval on Reducing Sugars (RS), Total Sugars (TS), Dry Matter (DM), Total Starch (TS), and Vitamin C. The total sugars and reducing sugars increased in the first 15 days in Kruda and Diamont, whereas in Desiree, it decreased from the start-up to the end of storage. Starch content in Kruda cultivar decreased regularly and the lowest quantity was recorded after 45 days of storage while in Diamont and Desiree, it showed increase and reached its peak level after 30 and 45 days of storage. The Cultivar Means showed that the highest dry matter (21.605 \%) was recorded in Diamont while the lowest was recorded in Desiree cultivar. Vitamin C decreased significantly in Diamont and Desiree cultivars in first 45 days of storage while minimum vitamin $\mathrm{C}$ was recorded in Kruda cultivar after 60 days of storage. The total decrease in Vitamin C remained about of $76 \%$ throughout the $90 \%$ storage. It is concluded that sweetening decreased in all cultivars during 90 days storage period at room condition. (Temperature 9$\left.18{ }^{\circ} \mathrm{C}\right)$. In Desiree cultivar, starch content is little affected by change storage duration, in case of sweeting i.e reducing sugar and total sugar did not occur in Desiree up to 90 days of storage. Therefore, the Desiree has maintained edible quality up to three months storage.
\end{abstract}

Received | October 31, 2019; Accepted | November 20, 2020; Published | February 08, 2021

*Correspondence | Shujaat Ali, Department of Horticulture Faculty of Crop Production Sciences, The University of Agriculture Peshawar, Khyber Pakhtunkhwa, Pakistan; Email: shujat.swati@gmail.com

Citation | Ali, S., T.A. Jan, K.U. Rehman, S.M. Khan, I. Hussain, W. Ahmad, Q. Ayub, M. Abbas and I. Ahmad. 2021. Effect of room condition on sweetening and other chemical components of different cultivars of potato in Swat District. Pakistan Journal of Agricultural Research, 34(1): 41-48.

DOI | http://dx.doi.org/10.17582/journal.pjar/2021/34.1.41.48

Keywords | Dry matter, Potato cultivars, Reducing sugars, Storage room condition, Total sugars, Total starch, Vitamin C

\section{Introduction}

$\mathrm{E}$ dible potato is stored in room condition to maintain their quality and marketable condition. Though the low-temperature storage reduces moisture losses and inhibits sprouting in the tubers but it brings changes in chemical components of tubers, affecting their cooking quality (Linus, 2014; Sudheer and Indira,
2007; Kazami et al., 2000). Starch is a major chemical component of the tubers which is about $60-80 \%$ of the potato dry matter. The dry matter (DM) is the major quality factor for processing of the tubers and the lower dry matter (DM) indicates the inferior quality chips and French fries (Miranda, 2006; Syed et al., 2018). In storage, conversion of ascorbic acid to dehydroascorbic acid takes place and further, to another form i.e. the 
diketogulanic acid. The former product is a useful form of ascorbic acid and has the vitamin c activity in the human body but the latter is not a nutritionally useful form, leading to loss of this vitamin during storage (Bergquist et al., 2006; Zeb et al., 2020).

Low-temperature sweetening is a well-known problem when the tubers are held for a longer period under cold storage condition. Starch and sugar are the major components of tubers and their inter-conversion during storage is a temperaturedependent phenomena. Sugar accumulation in the tubers takes place when the temperature of storage is $0-6{ }^{\circ} \mathrm{C}$, and only reducing sugars (RS) may contribute in the darkening of the processed products (Sandhu et al., 2002; Song, 2004; Yang, 2011). Though, sugar accumulation process is also affected by the rate of postharvest metabolism, variety and storage temperature (Kazami et al., 2000; De Wilde, 2005). Starch degradation into sucrose or glucose in respiration is a normal process which takes place in storage leading to the accumulation of reducing sugars that result in sweetening of the tubers. In nonenzymatic browning, elevated sugars in tuber react with amino acid during high temperature cooking which influences the color and flavor of the processed product (Hajirezaei, 2003). In reconditioning, the tubers having high reducing sugars are minimized when it is kept on around $10^{\circ} \mathrm{C}$ for some days, depending on the amount of sugar present (Sasak et al., 2004). This is a well-known industrial practice before processing of chips and French fries from potato (Smith etal.,2005). The present experiment was undertaken to study the sweetening process and other chemical components in three potato cultivars during 90 days of storage under room condition. Keeping the importance of potato in our diet, it is necessary to undertake research on the Chemical composition of the tubers and to monitor the changes in starch sugar conversion and other chemical component in storage and to establish the relationship with their quality.

\section{Materials and Methods}

The study "Effect of room condition on sweetening and other chemical components of different cultivars of potato in Swat District" conducted in Food Technology section, Agricultural Research Institute, Mingora, Swat, Pakistan in January, 2016-2017. Tubers of Diamont, Desiree and Kruda cultivars were collected from Agricultural Research Institute, Tarnab, Peshawar, KPK, Pakistan and stored at room condition (Temperature range $9-18^{\circ} \mathrm{C}$ ) for three months in three replications. Data on the chemical parameters such as reducing sugars (\%), total sugars, starch (\%), dry matter (\%) and vitamin C (mg /100 g) were recorded in three replications at 0 day(fresh) and after 15 days of interval. Minimum and maximum temperature and Relative Humidity (RH \%) data were recorded daily with the help of digital hygrometer.

\section{Temperature and relative bumidity}

Temperature and Relative Humidity \% (RH) data was recorded daily with the help of digital hygrometer, during the storage of three months at room condition. Which are given in the following Tables 1 and 2.

Table 1: Temperature and Relative humidity recorded data from 15, Jan up-to 29, February during storage at room condition.

\begin{tabular}{|c|c|c|c|c|c|c|c|c|}
\hline Jan & Temperature & RH \% & Feb & Temperature & RH \% & Feb & Temperature & RH \% \\
\hline 15 & 11 & 25 & 1 & 13 & 27.3 & 18 & 14 & 23 \\
\hline 16 & 13 & 26 & 2 & 14 & 26.6 & 19 & 15 & 21 \\
\hline 17 & 14 & 25.5 & 3 & 13 & 22 & 20 & 15.5 & 21.5 \\
\hline 18 & 15 & 25.5 & 4 & 14 & 18.3 & 21 & 15.5 & 21.5 \\
\hline 19 & 14 & 21.6 & 5 & 14 & 22.15 & 22 & 16 & 22 \\
\hline 20 & 14 & 19.1 & 6 & 14 & 22.15 & 23 & 15.5 & 20.5 \\
\hline 21 & 13.5 & 19.05 & 7 & 14 & 22.15 & 24 & 16.7 & 19.7 \\
\hline 22 & 13.5 & 19.05 & 8 & 14 & 26 & 25 & 17.2 & 11 \\
\hline 23 & 13 & 19 & 9 & 14.9 & 28 & 26 & 17.4 & 19.8 \\
\hline 24 & 13 & 19 & 10 & 15.2 & 28.8 & 27 & 17.2 & 23.9 \\
\hline 25 & 13.5 & 20.5 & 11 & 13 & 31 & 28 & 17.2 & 23.9 \\
\hline 26 & 14 & 22 & 12 & 13.5 & 28.84 & 29 & 17 & 23 \\
\hline 27 & 14 & 27 & 13 & 13.25 & 26.52 & & & \\
\hline 28 & 14 & 25.1 & 14 & 13.25 & 26.52 & & & \\
\hline 29 & 14 & 30.3 & 15 & 13 & 24.2 & & & \\
\hline 30 & 15 & 29 & 16 & 13 & 20.4 & & & \\
\hline 31 & 15.5 & 28 & 17 & 15 & 14.9 & & & \\
\hline
\end{tabular}


Table 2: Temperature and Relative humidity recorded data from 01, March up-to 14, April, during storage at room condition.

$\begin{array}{lllllllll}\text { March } & \text { Temperature } & \text { RH \% } & \text { March } & \text { Temperature } & \text { RH \% } & \text { April } & \text { Temperature } & \text { RH \% } \\ 1 & 17 & 22.8 & 16 & 15 & 35.5 & 1 & 18 & 38 \\ 2 & 17.5 & 26 & 17 & 15 & 37 & 2 & 15 & 35.5 \\ 3 & 18.5 & 27.1 & 18 & 15 & 38.5 & 3 & 15 & 35.5 \\ 4 & 15.3 & 28.6 & 19 & 15 & 37.8 & 4 & 12 & 33 \\ 5 & 15.3 & 28.6 & 20 & 15 & 37.8 & 5 & 12 & 32 \\ 6 & 15.3 & 28.6 & 21 & 15 & 37 & 6 & 17 & 33 \\ 7 & 12 & 30 & 22 & 15 & 34.8 & 7 & 17 & 32.4 \\ 8 & 12 & 30.6 & 23 & 15 & 34.8 & 8 & 14.8 & 34.8 \\ 9 & 12 & 28.6 & 24 & 12 & 32.5 & 9 & 14.8 & 34.8 \\ 10 & 12.5 & 30.5 & 25 & 11 & 35.4 & 10 & 14.8 & 34.8 \\ 11 & 13 & 36.5 & 26 & 14.4 & 34.4 & 11 & 12.5 & 37.2 \\ 12 & 14.5 & 37.3 & 27 & 14.4 & 34.4 & 12 & 15.5 & 33.7 \\ 13 & 14.5 & 37.3 & 28 & 17.8 & 34.3 & 13 & 15.5 & 33.7 \\ 14 & 16 & 38.5 & 29 & 18.2 & 36 & 14 & 18.5 & 30.1\end{array}$

\section{Estimation of reducing sugars (g/100 g)}

Reducing sugars and total sugars were estimated by the modified method of Miller (1972) in which 3,5, dinitro salicylic acid (DNSA) reagent was used to reduce glucose, giving reddish color and the concentration of red color was estimated by digital spectrophotometer (SP-300 Japan) on $540 \mathrm{~nm}$. A graph of different standard glucose concentration (20 $-100 \mu \mathrm{g}$ ) was also drawn at the same time.

\section{Materials}

1. Sodium potassium Tartrate (SPT)

2. 3.5. Dinitrosalicylic acid (DNSA)

3. Sodium hydroxide

4. Standard Glucose

\section{Reagents}

2 N sodium hydroxide solution: Weighted $84 \mathrm{~g}$ Sodium hydroxide $(\mathrm{NaOH})$ then dissolved in distilled water and putted $1 \mathrm{~L}$ volumetric conical flask.

Dinitrosalicylic acid (DNSA) reagent: Weighted 1 $\mathrm{g}$ DNSA and Dissolved in $50 \mathrm{ml}$ distilled water and $20 \mathrm{ml} 2 \mathrm{~N}$ Sodium hydroxide. After that, put $30 \mathrm{~g}$ Sodium Potassium Tartrate (SPT), and reached the volume upto100 $\mathrm{ml}$ by distilled water.

Total sugars (g/100g): For estimation of total sugars, $5 \mathrm{ml} 1+1 \mathrm{HCl}$ was added to $50 \mathrm{ml}$ diluted sample for inversion to reducing sugars, the sample was heated in digital water bath at $70{ }^{\circ} \mathrm{C}$ for 15 minutes.
Vitamin C content $(m g / g)$

\section{Iodometric (Redox) titration method for estimation}

of vitamin C: Vitamin C was estimated by Iodometric (redox) titration method Seamus Higson (2005) in which vitamin $\mathrm{C}$ was oxidized to dehydroascorbic acid by the acidified iodides ions. When all vitamin $\mathrm{C}$ was oxidized in the sample, the excess iodides ions were free to react directly with starch indicator, forming blue/back color which was the endpoint of the titration.

\section{Materials}

1. Potassium Iodate $\left(\mathrm{KIO}_{3}\right)$

2. Potassium Iodide (KI).

3. Sulfuric Acid

4. Standard Ascorbic acid.

5. Starch

\section{Reagents}

1 percent Starch Indicator: Putted one gram starch in hot $\mathrm{H}_{2} \mathrm{O}$ and reached the volume up to $100 \mathrm{ml}$ with distilled water.

Iodine solution: Add $30 \mathrm{ml}$ of $3 \mathrm{M}$ sulfuric acid.

1. Dissolved $0.268 \mathrm{~g}$ Potassium Iodate $\left(\mathrm{KIO}_{3}\right)$, Potassium iodide (KI) $5 \mathrm{~g}$ with $200 \mathrm{ml}$ distilled water.

2. Mix the solution

3. Putted the solution in $500 \mathrm{ml}$ graduated cylinder and make the volume up to $500 \mathrm{ml}$ by distilled water. 
Dry matter (g/100 g): Dry matter (\%) was estimated by oven drying method in which a weighed sample was kept at $70{ }^{\circ} \mathrm{C}$ temperatures for 18 hours and the dried sample was weighed till it reached its constant weight. The dry matter was calculated by the difference in fresh and after drying weight as Dry matter (\%).

$$
\text { Water content }(\%)=\frac{\mathrm{W} 1-\mathrm{W} 2 \times 100}{\text { Weight of sample }}
$$

Estimation of total starch $(\mathrm{g} / \mathbf{1 0 0} \mathrm{g})$ : Starch was estimated by the modified Macready method Yemm and Willis (1954), in which potato sample was first crushed, homogenized and washed with methanol/ chloroform/water (12:5:3) to remove water soluble sugars. The sample was centrifuged $3000 \times \mathrm{g}$ for 15 minutes and the precipitate was taken and kept in oven at $70{ }^{\circ} \mathrm{C}$ for 48 hours. Dried Starch sample was then solubilized with $52 \%$ perchloric acid and then diluted with the perchloric acid solution. The 30-50 $\mu 1$ sample was taken and treated in $4 \mathrm{ml}$ anthrone reagent $(200 \mathrm{mg}$ anthrone dissolved in $100 \mathrm{ml} 95 \%$ ice-cold Sulphuric acid). The sample was heated in digital water bath for 10 minutes, then cooled and the intensity of green color was determined as reducing sugar (\%) on $630 \mathrm{~nm}$ Digital Spectrophotometer (SP-300 Japan). A graph of different concentration of glucose sample $(5 \mu \mathrm{l}-25 \mu \mathrm{l})$ was also drawn at the same time. For starch determination, the reducing sugars values were multiplied by the factor of 0.90 .

\section{Material}

1. Anthrone in $95 \%$ ice-cold Sulphuric acid (prepared fresh daily)

2. Sulphuric acid

3. Standard Glucose

4. $2.5 \mathrm{~N} \mathrm{HCl}$

5. $52 \%$ perchloric acid

6. Methanol: Chloroform: Water (12:5:3).

\section{Results and Discussion}

\section{Reducing sugars (\%)}

Reducing sugars (glucose + fructose) are the major sugars in the potato tubers. In processed potatoes such as chips and French fries, the color of the product is dependent upon the concentration of reducing sugar (RS).In interaction, reducing Sugar values showed (Figure 1) a gradual decrease from 0 storage to the end of storage days. The Kruda cultivar showed highest values of reducing sugar at 0,15 and 30 days of storage period. In later storage days, the cultivar showed decreasing trend to the end of storage. Sugars are influenced by variety, location, cultural practices, and other so many factors however, respiration causes the conversion of starch to sucrose and then to reducing sugars in storage. Increase in reducing sugars content at low-temperature storage has been reported by many research workers (De Wilde et al., 2005). In this study, sweetening occurred in the first month of the storage but at later intervals, it decreased significantly as compared to zero storage. It is concluded that increase in sugar is a temperature-dependent phenomena and the temperature maintained at room condition was $\left(9-18^{\circ} \mathrm{C}\right)$.

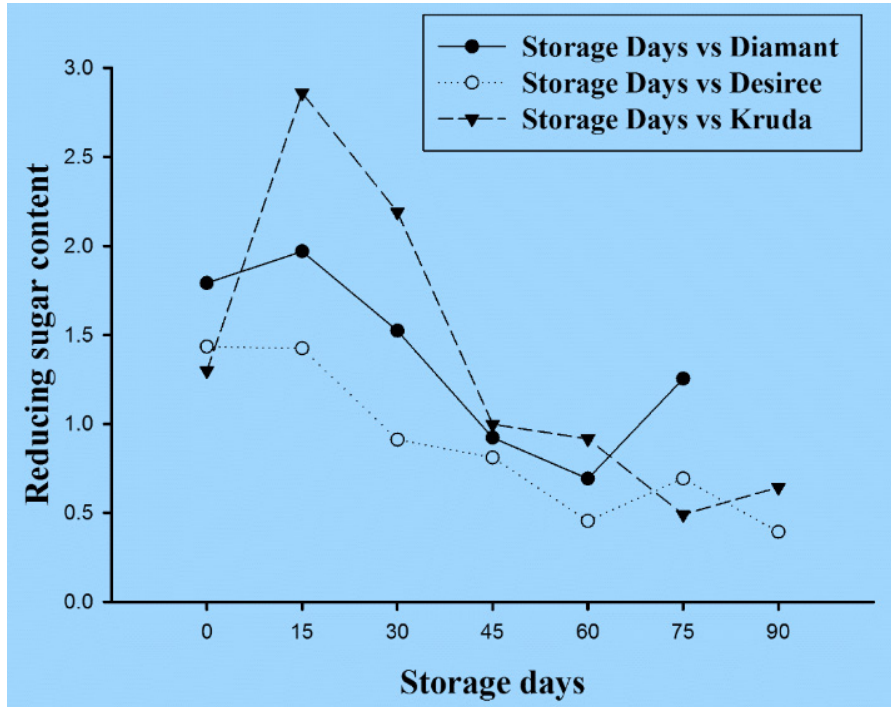

Figure 1: Reducing sugar ( $\mathrm{g} / 100 \mathrm{~g})$ of the three cultivars of potato during 3 months storage at room condition.

\section{Total sugar}

Total sugar comprised of glucose, fructose and sucrose which is formed during the respiration process and concentration of these components in storage, affect the quality of processed potato products. In interaction, Total sugar at 0 and 15 days remained highest in Diamont and Kruda cultivars (Figure 2). While in Desiree cultivar, it showed decreasing trend from the start to the end of the storage period. It is been reported that sugar showed sharp increase particularly sucrose in potato tubers when the storage temperature was $8^{\circ} \mathrm{C}$ or $10^{\circ} \mathrm{C}(\mathrm{Olsson}, 2004)$. Similarly, mean total sugar in the range of $0.69 \%$ reported in both Desiree and Diamont cultivars (Ghulam et al., 2011; Abdur et al., 2017).

\section{Starch (\%)}

Starch is the major component of potato D.M, consisting of $60-80 \%$ starch. It is composed of two 
subunits, i.e. amylose and amylopectin which are 21$25 \%$ and $75-79 \%$, respectively. In interaction (Figure 3 ), increasing trend was recorded in Desiree from 0 storage to 45 days and at this period reached its peak level. While in Kruda, a decreasing trend was recorded from 0 days to 45 days in storage and reached its minimum level at that period. Minimum starch in Diamont was recorded in at 90 days while maximum was recorded at 30 days of storage. Various pre-harvest factors such as genotypes, cultural practices, weather conditions and water stress affect the quantity of starch in the tubers. It has been reported that 11.02 $\%$ and $14 \%$ starch in Desiree and Diamont cultivars (Ghulam et al., 2011). In this study, the slight increase in starch content was recorded in Desiree cultivar while an irregular decrease was recorded in Kruda cultivar during 90 days of storage.

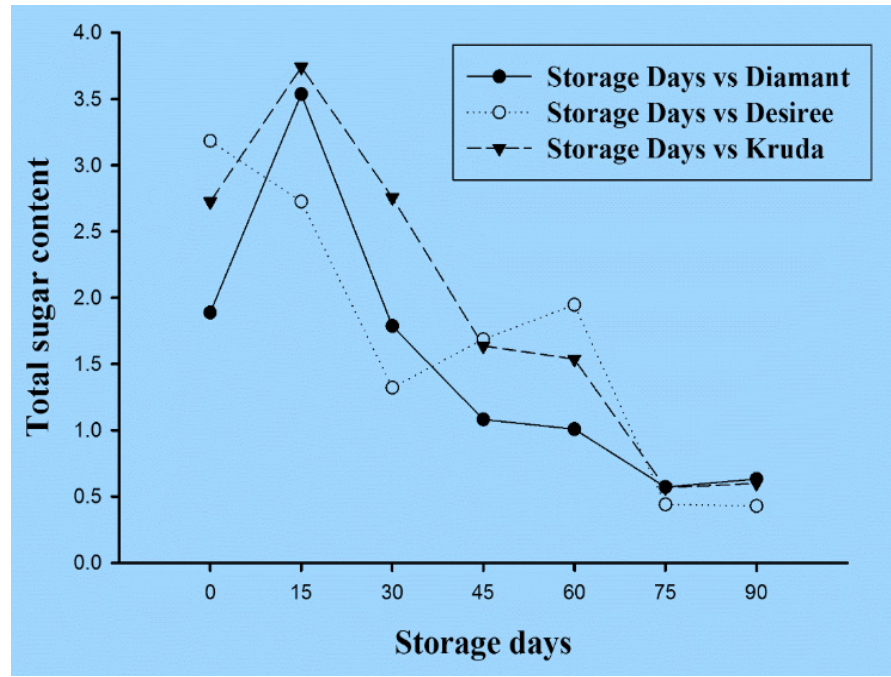

Figure 2: Total sugar $(g / 100 \mathrm{~g})$ of the three cultivars of potato during 3 months storage at room condition.

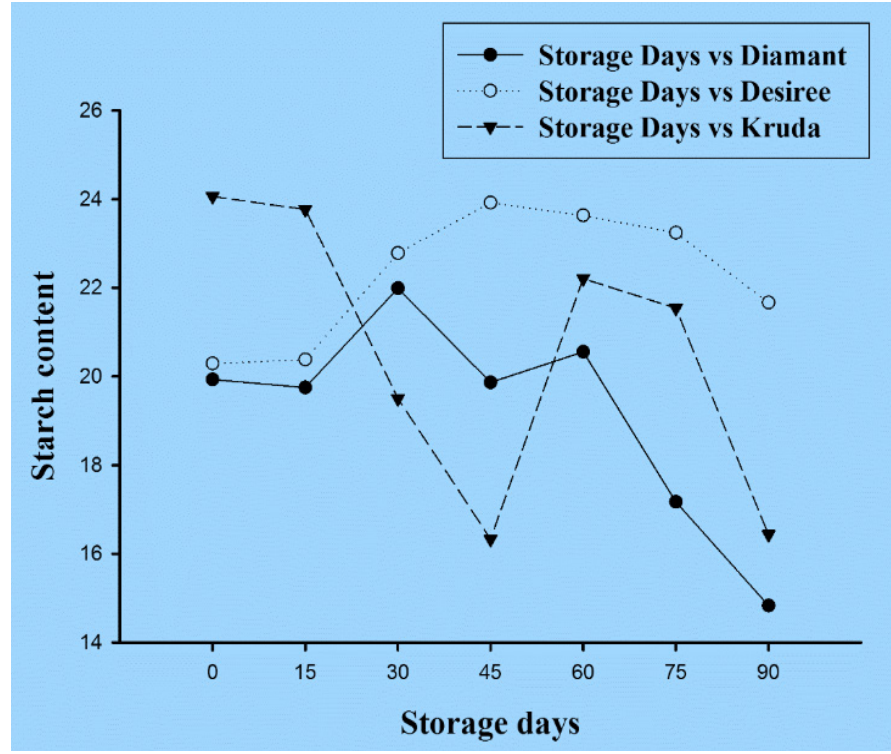

Figure 3: Starch content $(\mathrm{g} / 100 \mathrm{~g})$ of the three cultivars of potato during 3 months storage at room condition.
Dry matter (\%)

Data regarding dry matter revealed that interaction means showed statistically significant differences (Figure 4). In interaction, mean values of the dry matter exhibited the lowest values in Diamont and Desiree at 45 days of storage period. The reason may that sprouting initiated after 45 days in storage. At later storage, dry matter slightly increased in both the diamond and Desiree cultivars. In Kruda, dry matter decreased in the first 30 days of storage while at later storage, it slightly increased (Syed et al., 2018). Also recorded maximum dry matter $(23 \%)$ in genotype NARC 2008-C of Potato, while lowest DM was recorded in NARC 2008-F genotype. Dry matter is an important quality criterion for process products and is influenced by several factors such as cultivars, maturity, climate, soil, and fertilizers application (Salaman and Redcliffe, 2014). It has been reported that dry matter should be more than $20 \%$ for chips, French fries and dehydrated products (Rana and Rajesh, 2011). Dry matter is strongly genetic based character and differed considerably between cultivars (Abbas et al., 2011).

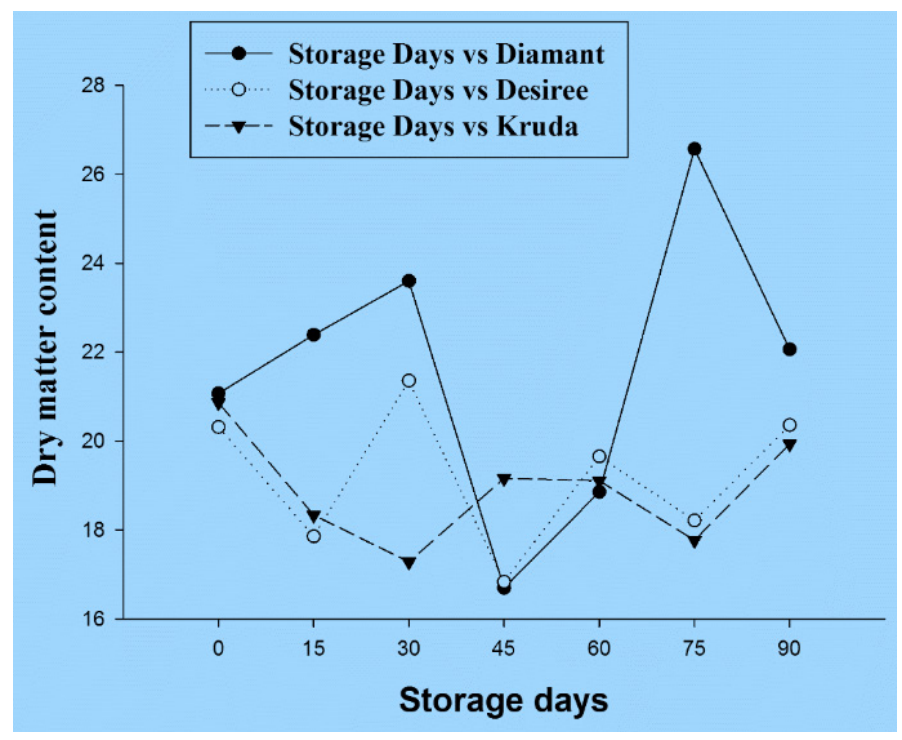

Figure 4: Showing the dry content $(g / 100 \mathrm{~g}$ ) of the three cultivars of potato during 3 months storage at room condition.

\section{Vitamin C $(m g / 100 \mathrm{~g})$}

Vitamin $\mathrm{C}$ is an important antioxidant present in the tubers of potato which carries many health benefits. In interaction (Figure 5), it decreased significantly from 0 to 45 days of storage in both Diamont and Desiree cultivars while the decrease remained up to 60 days in Kruda cultivar. The sharp decrease in vitamin $\mathrm{C}$ from 0-45 days of storage in almost all cultivars may be due to the initiation of sprouting (Jan et al., 2017). Losses in vitamin $\mathrm{C}$ have been reported many research 
workers in different vegetables (Cho et al., 2013; Shah et al., 2019). Similarly, the Sharpe decrease in total ascorbic acid content occurred during the first three to four months of storage at $7{ }^{\circ} \mathrm{C}$ (Külen et al., 2013). Moreover, $40-60 \%$ decrease have been reported over for course of several months (Galani et al., 2017; Külen et al., 2013). Zeb et al., 2020, also investigated the decreasing trend in Sweet orange during storage for 48 days. These results has been confirmed by the previous workers conducted in the past.

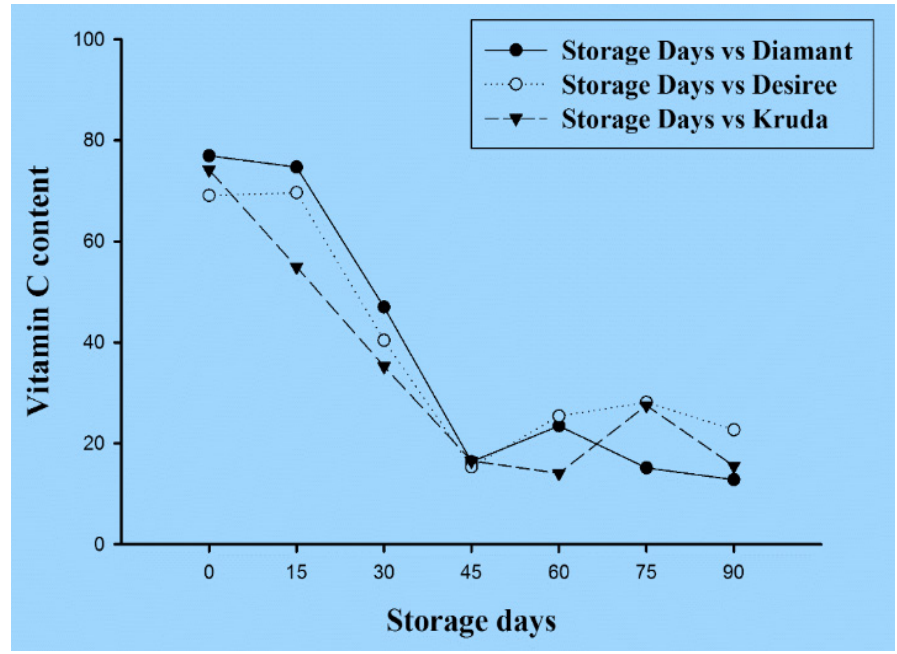

Figure 5: Vitamin C content ( $m g / 100 \mathrm{~g}$ ) of the three cultivars of potato during 3 months storage at room condition.

\section{Conclusions and Recommendations}

About $78 \%$ Vitamin C (mg/100 g) was lost in the first $45 \%$ days of storage while after 90 days of storage, total losses remained about $77 \%$. In Desiree, starch content is little affected by a change in storage temperature, indicating that starch has shown resistance to convert into sugar. This characteristic is a good characteristic of the Desiree cultivar which does not allow the sugar accumulation during storage. Sweetening due to reducing sugars and total sugars did not occur in Desiree cultivar 90 days of storage while Diamont and Kruda cultivars showed sugar accumulation at some storage intervals. Therefore, it can be concluded that Desiree has maintained edible quality during storage.

\section{Acknowledgements}

This project was granted by the bilateral agreement between Agricultural Research Institute, (N), Mingora, Swat- Pakistan on behalf of the Department of Horticulture, Khyber Pakhtunkhwa Agriculture University, Peshawar-Pakistan. The Authors wish to thanks SRO Mr. Tariq Ahmad Jan who, provided financial support for this work.

\section{Novelty Statement}

The main objective of this paper is to undertake research on the chemical composition of the tubers and to monitor the changes in starch sugar conversion and other chemical components in storage and to establish the relationship with their quality.

\section{Author's Contributions}

Senior research officer Mr. Tariq Ahmad Jan guided Physical and chemical attributes of various cultivars of Potato Tubers, Dr. Khalil Ur Rehman designed the experiment in Food Technology Research Institute District Swat, while the rest of authors, did most statistical analysis.

\section{Statement of conflict of interest}

The authors have declared no conflict of interest.

\section{References}

Abbas G., K. Farooq, I. Hafiz, A. Hussain, N. Abbasi and G. Shabbir. 2011. Assessment of processing and nutritional quality of potato genotypes in Pakistan. Pak. J. Agric. Sci. 48(3): 169-175.

Abdur, R., S. Ali, T.A. Jan, T. Hussain, S. A.S. Bacha, B.Zeb and T.H. Khan. 2017. Changes in physio-chemical composition of potato tubers at room storage condition. Sci. Int. (Lahore), 29(1): 179-183.

Bergquist, S.Å., U.E. Gertsson and M.E. Olsson. 2006. Influence of growth stage and postharvest storage on ascorbic acid and carotenoid content and visual quality of baby spinach (Spinacia oleracea L.). J. Sci. Food Agric., 86(3): 346-355. https://doi.org/10.1002/jsfa.2373

Cho K.-S., H.-J.Jeong, J.-H. Cho, Y.-E. Park, S.-Y. Hong, H.-S. Won and H.-J. Kim.2013. Vitamin C content of potato clones from Korean breeding lines and compositional changes during growth and after storage. Hortic. Environ. Biotechnol., 54(1): 70-75. https://doi.org/10.1007/s13580013-0089-8

De-Wilde, T., B. De-Meulenaer, F. Mestdagh, Y. Govaert, S. Vandeburie, W. Ooghe, S. Fraselle, K. Demeulemeester, C. Van Peteghem and A. 
Calus. 2005. Influence of storage practices on acrylamide formation during potato frying. J. Agric. Food Chem., 53(16):6550-6557.https:// doi.org/10.1021/jf050650s

Galani, J.H.Y., P.M. Mankad, A.K. Shah, N.J. Patel, R.R. Acharya and J.G. Talati. 2017. Effect of storage temperature on vitamin $\mathrm{C}$, total phenolics, UPLC phenolic acid profile and antioxidant capacity of eleven potato (Solanum tuberosum) varieties.Hortic.PlantJ.,3(2):73-89.

Ghulam, A., K. Farooq, I.A. Hafiz, A. Hussain, N.A. Abbasi and S. Ghulam. 2011. Assessment of processing and nutritional quality of potato genotypes in Pakistan. Pak. J. Agric. Sci., 48(3): 169-175.

Hajirezaei, M.R., F. BoÈrnke, M. Peisker, Y. Takahata, J. Lerchl, A. Kirakosyan and U. Sonnewald. 2003. Decreased sucrose content triggers starch breakdown and respiration in stored potato tubers (Solanum tuberosum). J. Exp. Bot., 54(382): 477-488. https://doi. org/10.1093/jxb/erg040

Higson, S.P.J., 2005. Analytical chemistry, Oxford University Press.

Jan, T.A., S.A. Ali, T. Rab, S.A.S. Hussain, B. Bacha, B.Zeb and T.H. Khan. 2017. Changes in physio-chemical composition of potato tubers at room storage condition. Sci. Int. (Lahore), 29(1): 179-183.

Kazami, D., T. Tsuchiya, Y. Kobayashi and N. Ogura. 2000. Effect of storage temperature on quality of potato tubers. Nippon Shokuhin Kagaku Kogaku Kaishi. J. Jpn. Soc. Food Sci., 47(11): 851-856. https://doi.org/10.3136/ nskkk.47.851

Külen, O., C. Stushnoff and D.G. Holm. 2013. Effect of cold storage on total phenolics content, antioxidant activity and vitamin $\mathrm{C}$ level of selected potato clones. J. Sci. Food Agric., 93(10): 2437-2444. https://doi.org/10.1002/ jsfa.6053

Linus, B., 2014. Evaluation of the efficacy of three organic extracts in controlling storage rot in Sweet Potato.

Miranda, M.L. and J.M. Aguilera. 2006. Structure and texture properties of fried potato products. Food Rev. Int., 22(2): 173-201. https://doi. org/10.1080/87559120600574584

Miller, G.L., 1972. Use of dinitrosalicylic acid reagent for determination of reducing. January 2016. 2(1): 6 .
Olsson, K., R. Svensson and C.A. Roslund. 2004. Tuber components affecting acrylamide formation and colour in fried potato: Variation by variety, year, and storage temperature

and storage time. J. Sci. Food Agric., 84(5): 447458. https://doi.org/10.1002/jsfa.1681

Rana, R.K., 2011. The Indian potato-processing industry: Global comparison and business prospects. Outlook Agric., 40(3): 237-243. https://doi.org/10.5367/oa.2011.0057

Salaman, R.N., 2014. Potato varieties: Cambridge University Press.

Sandhu, K., A. Bal and P. Ahluwalia. 2002. Studies on suitability of cultivar, frying medium and packaging for potato chips. J. Food Sci. Technol., 39(4): 394-402.

Sasaki-tamaki, D., K. Perez, J.-I. Himoto and K. Itoh. 2004. Effects of reconditioning on the quality of different processing potato cultivars after low temperature storage. Food Preserv. Sci., 30(3): 129-135. https://doi.org/10.5891/ jafps.30.129

Shah, S.M., N. Ara, A. Ullah, S. Ali, S.H.A. Shah, I. Khan, H.A.S. Syed, A.K. Intikhab, A. Badshah and K. Ghufran. 2019. Evaluation of physico-chemical characterization of tomato. (Lycopersicon esculentum Mill.) Germplasm.

Smith, A.M., S.C. Zeeman and S.M. Smith. 2005. Starch degradation. Annu. Rev. Plant Biol., 56: 73-98.

Song Y.-S. 2004. Genetic marker analysis in potato for extreme resistance (Rysto) to PVY and for chip quality after long term storage at $4 \mathrm{C}$, Technische Universität München.

Sudheer, K. and V. Kazami. 2007. Post-harvest technology of horticultural crops: New India Publishing.

Syed, M.A., S. Ali, A. Iftkhar, S.A. Syed, K.A. Muhammad, S.M. Rahmatullah, K. Syed and H. Imran. 2018. Evaluation of the growth and physico-chemical composition of different genotypes of potato. Sci. Int. (Lahore), 30(3): 371-374.

Yang, Y., X. Qiang, K. Owsiany, S. Zhang, T.W. Thannhauser and L. Li. 2011. Evaluation of different multidimensional LC-MS/ MS pipelines for isobaric tags for relative and absolute quantitation (iTRAQ)-based proteomic analysis of potato tubers in response to cold storage. J. Proteome Res. 10(10): 46474660. https://doi.org/10.1021/pr200455s 
Yemm, E. and A. Willis. 1954. The estimation of carbohydrates in plant extracts by anthrone. Biochem.J.,57(3):508.https://doi.org/10.1042/ bj0570508

Zeb, A., A. Rab, A. and S. Ali. 2020. Effect of location on physico-chemical composition and storage duration of sweet orange (Blood red). Pak. J. Agric. Res., 33(2): 316-320. https://doi. org/10.17582/journal.pjar/2020/33.2.316.320 